\title{
ARTICLES
}

\section{Joan Maragall: creació, traducció i reescriptura}

\section{Joan Maragall: creation, translation and rewriting}

\author{
Francesco Ardolino \\ Universitat de Barcelona \\ ardolino@ub.edu
}

\begin{abstract}
What is the role of translation in Maragall's work? If his first goal was to bestow cultural support to Catalan literature with the addition of the European authors of Modernism, the second stage of the Catalan poet's agenda becomes more ambitious, delving into the origins of Western literature and culminating in the translation of the Homeric Hymns.

My contribution analyzes how, on the one hand, the Catalan rewriting of the works of Nietzsche, Goethe, Novalis, or Dante draws a progressive and continuous line within Maragall's ideas; and, on the other hand, what impact these versions have on his own literary creation, through the loanwords that spread across his translations, and his poetry.
\end{abstract}

Keywords: Joan Maragall, translation, rewriting, poetry and poetics

\section{INTRODUCCIÓ}

Il est certes peu banal, il est même curieux, de voir dans le germanisme le premier caractère du génie de Maragall; il faudrait, avant tout, nous montrer combien il est catalan, par sa sincérité d'expression, par sa netteté de vision, et même par la substance "terrienne" 
de son mysticisme. [...] On m'objectera que Maragall a traduit Goethe. Je répondrai que Goethe aimait les dieux de la Grèce. [...] Maragall est un poète essentiellement moderne et naturiste; à de certains égards, il fait penser à notre Francis Jammes, qui n'est pas germain. Il fait penser a Francis Jammes, parce que sa poésie s'applique aux êtres immédiats, à l'horizon ordinaire, à la vie un peu monotone qui nous entoure. (Pons, 1914, p. 189)

La controvèrsia sobre la múltiple ànima maragalliana no només alimentava el debat pocs anys després de la seva mort, sinó que també reactivaria la interpretació de les seves tries com a traductor. El recorregut de les versions que l'autor català fa com a torsimany de l'alemany, del francès, del grec antic, de l'italià i, potser, de l'anglès no assenyala pas un camí estrafolari ni un seguit desordenat de punts en un mapa; ans al contrari, la lògica interna que regla les seves decisions procedeix en paral lel amb la resta de la seva creació literària. Tanmateix, no vull posar el carro davant els bous i, en lloc de presentar una tesi ja confegida, m'estimo més parlar de dues hipòtesis de treball, que són:

1) Les traduccions fetes per Joan Maragall representen un conjunt coherent i no pas un seguit d'encaterinaments aleatoris lligats als èxits literaris del període.

2) Les seves versions i la producció literària original tenen unes correspondències transitives $i$, en el pla lingüístic $i$ conceptual, funcionen com una sèrie de vasos comunicants.

\section{A LA RECERCA D’UN PARADIGMA}

Comencem amb la primera hipòtesi. Les pàgines que ocupen, dins la seva obra, les versions d'altres autors, formen el grup més consistent de textos escrits per Joan Maragall en comparació amb altres gèneres, com ara la poesia, la prosa periodística o la tractadística -més difícil és el parangó amb la prosa epistolar, atès que no se'n pot recopilar un corpus complet. Els noms dels autors estrangers traduits en obres publicades i manuscrits no provoquen grans sorpreses. D'una banda, hi ha Goethe, Novalis i Nietzsche, que arrosseguen un estol d'escriptors de llengua alemanya amb presència molt més reduïda que van des d'Adelheid Wette, autora del Ton i Guida (això és, Hänsel und Gretel), fins a Wagner, i que inclouen les lletres afegides a les peces d'altres compositors, en alemany i també en francès, que Maragall traslladava per als programes de mà de l'Orfeó Català. D'acord, aquí caldria distingir entre les feines fetes per encàrrec i els projectes propis, però, mutatis mutandis, tot cap dins el mateix sac modernista que pretén acostar l'escriptura en català als models europeus contemporanis. D'altra banda, trobem els Himnes Homèrics; 1'“Olímpica Primera” i l'himne "A Hieró de Siracusa" de Píndar; un intent incipient de traducció de la Teogonia d'Hesíode i la "Cançó d'Harmodi" de Cal-lístrat -en realitat, "uns breus escolis anònims" (Torné, 1999b, p. 139)-. Enmig resten materials escampats que, aparentment, no en- 
caixen dins cap ordre preestablert. Una "Salutació" de Carmen Sylva, publicada en un llibre multilingüe que recull els textos dels Jocs Florals de Colònia de 1899, entra dins les versions de circumstàncies; però hi ha, com a mínim, dos textos que remeten a unes causes del tot diferents. El primer és Fisionomías de Santos d'Ernest Hello. Per què Maragall es compromet a portar a terme, en castellà, una obra hagiogràfica que no correspon ni als seus interessos com a escriptor ni a les seves pruïges intel·lectuals? Ignasi Moreta (2014) demostra que el traductor se'n penedeix de seguida i fins en el pròleg fa patent una certa incomprensió respecte a Hello, en catalogar-lo com a "neocatòlic". A poc a poc filtra el propi descontent respecte a la feina que ha de complir: s'hi hauria de dedicar del tot, diu a l'amic Roura el 17 de març de 1899, "però si vols que et diga la veritat ja em pesa; l'autor mateix decau, i ja voldria haver-m'ho tret de davant" (Maragall, 1960, p. 1129). A banda d'aquestes consideracions, cal recollir el suggeriment de Moreta (2014, p. 121), segons el qual la connexió de Maragall amb Hello podria haver-se produït mitjançant Huysmans, amb Là-bas (1891), on podem llegir apreciacions si no del tot iròniques, com a mínim ambigües: "Le véritable psychologue du siècle, se disait Durtal, ce n'est pas leur Stendhal, mais bien cet étonnant Hello dont l'inexpugnable insuccès tient du prodige!" (Huysmans, 1895, p. 18).

L'altre text en qüestió és heterodox fins i tot per la llengua d'origen. Maragall s'encara a la versió d'una cançó de La Vida Nova de Dante. A hores d'ara, no tenim constància d'altres traduccions de l'italià fetes pel poeta i és just demanar-se d'on li venia l'impuls per emprendre aquesta tasca. Hom ha resseguit parcialment les fases amb què el text arriba a les pàgines de la revista Lletres l'abril de 1907, però el que no s'ha pogut esbrinar són les motivacions per les quals Maragall escull un poema que: a) ja havia estat traduït (i publicat en llibre) per Manuel de Montoliu, amb qui tenia una relació prou íntima; b) és d'un autor, l'Alighieri, que ell estava estudiant minuciosament, en aquells anys, perquè volia fer servir alguns cants de la Divina Comèdia com a base teòrica per a la redacció de l'“Elogi de la Paraula" -i encara més per a l'Elogi de la Poesia- ${ }^{1}$.

A banda de tot això, descarto de l'anàlisi el text de la conferència El trevall [sic] de John Ruskin, amb data de 1903. Malgrat la congruència d'aquest llibret amb els interessos culturals del poeta català, l'única prova d'autoria la certificarien les inicials del traductor, $J M$, que, em sembla, demostren més aviat el contrari: per què Maragall no hauria volgut signar el resultat del seu esforç? A més a més, un examen estilístic ens fa dubtar des del primer moment: només cal dir que hi domina la fórmula d'obligació tenir de, fet gens habitual dins els usos lingüístics de l'autor².

\footnotetext{
${ }^{1}$ Afegeixo, a la normal distinció gràfica entre articles i llibres (l'Elogi de la Poesia és un volum), un nou element: quan parlo d'Elogis en general (però també com a gènere), faré servir la fórmula en rodona i lletra inicial en majúscula, segons els criteris de la revista Haidé. Estudis maragallians.

${ }^{2}$ La primera llança a favor de la paternitat maragalliana la va trencar Maria Àngela Cerdà i Surroca (1981, p. 202-203), que es basa en les dades de la publicació del text -va aparèixer a la revista Catalunya, on Maragall ja havia col-laborat- $\mathrm{i}$ en el genèric interès del poeta per Ruskin. Una reticència explicita
} 
Com a curiositat, vull assenyalar el manuscrit mrgll-Mss. 7-22-3/2, que ha quedat catalogat durant dècades a l'Arxiu Joan Maragall com una traducció d'un text d'autor no identificat i que ja puc atribuir a Edvard Grieg. Es tracta de Våren (op. 33/2), "La primavera", també coneguda amb el títol "L'última primavera", per com la va rebatejar el seu torsimany alemany, Hans Schmidt (Foster, 2007, p. 128). La recerca ha estat difícil i laboriosa, però m'hi va ajudar la similitud amb la versió que Miquel de Palol (2016, p. 255) va dedicar al músic, probablement l'any 1907, en ocasió de la seva mort.

Amb aquestes amputacions, tornem a la citació inicial de Josep Sebastià Pons, que se'ns mostrarà encara més fidedigna si la comparem amb l'afirmació que Ramon Torrent (2011, p. 315) formularia, un centenar d'anys més tard, segons la qual "la influència de Goethe [portà Maragall] a familiaritzar-se amb els clàssics antics grecs i llatins" i a mantenir la "tensió entre el romanticisme germànic i el classicisme humanista mediterrani, els dos pols que travessen la seva trajectòria sencera de poeta traductor o de traductor poeta".

Fet i fet, les Elegies Romanes o la Ifigènia a Tàurida d'una banda, i els Himnes Homèrics de l'altra, per agafar els textos més representatius dels dos grups, marquen també dues extremitats cronològiques dins la biografia de l'autor. La passió per Goethe va començar a la joventut, i durarà tota la vida, com ho testimonien les versions publicades $i$ la pila de provatures inèdites $i$ inacabades que va escriure al llarg d'un quart de segle; la mirada en la Grècia clàssica, en canvi, Maragall la fixarà molt més tard, després de l'esclat de la reflexió metapoètica dels Elogis que arriba a coincidir amb les versions de Novalis i de Dante.

Finalment, no oblidem que la connexió entre Goethe i el món clàssic el poeta català la manifesta, la ressalta i la reivindica fins i tot a la introducció de la Nausica:

$$
\text { [...] vull retreure }
$$

els mots divins d'Homer, en un teatre, per refrescar-m'hi el cor en sos meandres i fer-me nou lo vell. I en dec la idea al poeta més gran de l'Alemanya.

$$
\text { (v. } 9-13)^{3}
$$

Evidentment, "Maragall elegí, entre els moderns, Goethe, i d'aquest, allò que estava més vinculat a la tradició greco-llatina" (Valentí, 1973, p. 60). D'acord, però aquest transvasament ha de passar, a fortiori, a través d'una nova interpretació de

\footnotetext{
a aquestes raons d'escassa envergadura la manifestà Lluís Quintana (1996, p. 308): "La traducció és força matussera, hi falten fragments de l'original $i$ el traductor hi posa notes a peu de pàgina: tot plegat fa difícil pensar que sigui de Maragall". Encara més contundent va ser Jaume Aulet (1992, p. 145), que l'atribueix a Jeroni Martorell.

${ }^{3}$ Totes les citacions de la poesia de Maragall les extrec del primer volum de les Obres Completes a cura de Lluís Quintana i Ignasi Moreta (Maragall, 2020), després d'eliminar-ne els signes d'interrogació d'obertura: no n'indicaré els números de pàgina. El mateix tractament el reservaré per als Himnes homèrics.
} 
la paraula "tragèdia" aplicada a la Nausica. La qüestió, elegantment esquivada per Carles Riba, ha estat examinada per Carles Miralles (2003, p. 734) segons dues perspectives: 1) interpretar el mot amb el significat de "cosa extraordinària, inoïda, tràgica perquè mostrava les il·lusions, els sentiments d'amor no correspost d'una noia excellent i tan bella"; i/o 2) acceptar l'antinòmia entre l'experiència (Ulisses) i la bellesa (i les seves hipòstasis, entre les quals, la poesia) per dotar el terme d'un valor simbòlic afegit. En aquesta segona línia es podria col·locar una posició ulterior, segons la qual la tragèdia s'esdevé en la separació de la unitat andrògina representada per Ulisses i Nausica. Però això implicaria rellegir el text no a partir d'unes aparicions de l'autor en travestí (Ardolino, 2006, p. 78) o "encarnant meravellosament el personatge de la noia" (Cornudella, 2018, p. 43), sinó com un cant amebeu on l'escriptor modula, al compàs de dues veus diferent, un únic discurs sobre l'abandonament.

\section{UN BITLLET D’ANADA I TORNADA}

Dit això, el que pretenc remarcar és el continuum literari i ideològic en què Maragall fonamenta íntegrament la seva producció. Abans de proposar uns exemples, però, necessitaré un suport bàsic on col·locar aquesta dialèctica entre original d'autor i versió; i per això he de fer cap a uns minima methodologica:

Quan l'exercici de la traducció, i encara més el de la traducció poètica, es realitza des de la perspectiva vital i professional de l'escriptor, és lògic i és gairebé d'esperar que entre textos traduïts i textos de creació es produeixi, diguem-ne, un vaivé [...] de trets estilístics, de recursos retòrics, de costums o tics lingüístics, i fins i tot de principis de poètica, de mirades estètiques o de postures ideològiques. (Gavagnin, 2007, p. 61)

Comencem pel cas més fàcil. Entre les cartes a l'amic Lloret, hi ha un parell d'epístoles poètiques, en castellà, sense cap pretensió literària que, tanmateix, contenen una forta càrrega de sinceritat autobiogràfica. Agafem la conclusió de la més llarga, amb data del 26 de gener de 1886:

¡Ah! sí, quiero ser sabio,

Y cuando llegue a la ansiada meta,

Galana frase y oración discreta

Han de brotar de mi erudito labio.

¿Quiero llegar a algo!

¿Quiero saberlo todo!

Y después buscaré oportuno modo

De que sepan las gentes lo que valgo.

(Maragall, 2007, p. 92) 
Dubto que Maragall vulgui fer l'ullet al seu amic amb l'esperança que hi desxifri la citació amagada; més aviat, m'inclino per veure-hi la dificultat d'allunyar-se d'un model massa enlluernador, com ara el de Goethe. Sigui com sigui, aquesta "microseqüència" és extreta ipso facto del Faust i, en particular, del diàleg de l'estudiant amb Mefistòfil que, en la versió castellana de Maragall, deia: "Querría ser muy sabio: abarcar todo lo del cielo y la tierra, la ciencia y la naturaleza". I també el consell anterior, el d'atenir-se a les paraules, ressona com un eco dins el vers maragallià "Galana frase y oración discreta". No hi insisteixo; però, abans de passar a Novalis, he de mencionar que, per a una anàlisi específica de la traducció del Faust, encara és essencial el volum de Jaume Tur (1974) tal com assenyala, en temps molt recents, Josep Murgades (2019).

Enric d'Ofterdingen és de 1907, tot i que la primera coincidència ens porta molt enrere en el temps. A la "Nota autobiogràfica" de 1885, Maragall, recordant el seu ingrés a la Universitat, comentava: "tot això fou per mi com una terra de promisió, com si entrés en ma pàtria després d'una ausència casi inmemorial"4 (Maragall, 2007, p. 183). La frase és molt semblant a la cavil·lació de l'Enric que, tot just començar el seu viatge cap a Augsburg, "tenia al davant la flor de la meravella, i mirava la Turíngia, que ara deixava endarrere, amb l'estranya impressió de com si [...] tornés a la seva pàtria, com si el seu viatge fos envers ella". Massa anys corren entre la "Nota" i la traducció que acabo de citar per justificar una remembrança concreta; i massa genèrica és l'expressió perquè se'n pugui treure cap conclusió. Les coses canvien si donem fe al Maragall prologuista que ens avisa, de bell antuvi, que el text de Novalis és "una novel'la per a poetes". En aquest cas, hem de graduar d'una manera més adequada la nostra lupa i cercar i ressaltar una altra tipologia de fragments. Arribem, doncs, al capítol IX de la Primera Part, quan l'Enric es troba sol amb la Matilde i li confessa:

Oh, estimada! El cel te m'ha donat per adorar-te. I jo a tu faig oració. Tu ets la santa que presentes a Déu els meus desitjos, i a través de qui ell se'm manifesta i me dona a conèixer la plenitud del seu amor. Què és la religió sinó l'acord infinit, l'eterna unió dels cors aimants? Allí on dos s'estimen, allí és Déu amb ells.

Interrompo l'enamorat per donar la paraula al poeta d'“Haidé":

Ella digué son nom; llavors la vella

que li era a la vora va dir: "Per quin sant és?".

${ }^{4}$ Amb el manuscrit davant, esmeno l'article una pel possessiu ma. Les citacions de l'Enric d'Ofterdingen procedeixen de l'edició que he preparat per al cinquè volum de les Obres completes dedicat a les traduccions que no es publicarà abans de 2023; per això no hi poso els números de pàgines.

5 "Die Wunderblume stand vor ihm, und er sah nach Thüringen, welches er jetzt hinter sich ließ mit der seltsamen Ahndung hinüber, als werde er nach langen Wanderungen von der Weltgegend her, nach welcher sie jetzt reisten, in sein Vaterland zurückkommen, und als reise er daher diesem eigentlich zu" (Novalis, 2016, p. 12). 
I respongué l'amiga amb els ulls riallers:

"Això rai, tant se val, la santa és ella".

Ella és la santa d'ella perquè és bella

i Déu li ha fet la gràcia de llençar llum entorn;

ella és el sol del seu propi jorn

i de sa nit l'estrella.

Si l'íncipit d"'Haidé" corre a frec de l'heretgia, l'Enric de Novalis, en la traducció de Maragall, ja predica el panteisme i, passant per una imatge que sembla realitzar-se pictòricament una vintena d'anys més tard en un quadre de Pierre-Paul Prud'hon ( $L$ 'âme brisant les liens qui l'attachent à la terre), al capítol VIII pregunta:

I qui sap si encara un dia el nostre amor se'ns tornarà ales de foc que ens duran d'un vol a la nostra pàtria celestial abans que la vellesa i la mort ens prenguin. No ha estat ja un miracle el que tu sies meva, que jo et tinga ara en els meus braços, i que tu m'estimis i vulguis ésser meva eternalment?

Els ecos, aquest cop, procedeixen d'"El Comte Arnau": "Arnau, si jo era teva, no eres meu?", implora l'Adalaisa, desesperada. I el Comte li respon: "Jo soc sols dels meus braços i els meus passos" (v. 239 i 240) amb uns dels versos més prosaics de la literatura catalana, si no fos que la seva potència ressona entre aquelles vocals enfosquides $(o / u)$ i aquelles consonants sibilants que s'allarguen com un eco demoníac.

\section{EL FUTUR EN EL PASSAT}

Ara, d'una banda, caldria resseguir les reflexions de l'autor, al centre de les quals es col-loca l'article "Traducciones" de 1901, en el qual, segons Eisner (2009, p. 753) "se decanta claramente por la llamada «traducción viva», que implica la adaptación de la lengua y el universo contenidos en la obra original a una lengua y a un universo catalanes". De l'altra, valdria la pena esbrinar com les traduccions de Maragall, i especialment les de Goethe, s'han orientat cap a aquest aspecte creatiu. Dins una bibliografia que va des de les indicacions de fonts de Manuel de Montoliu (1935) fins a l'estudi de la recepció maragalliana del Romanticisme per Magdalena Bosch Rabell (2018), passant per la recerca metòdica de Roser Campi (2000), m'adreço cap a Martí Duran perquè la seva mirada s'assembla molt a la perspectiva metodològica de la meva recerca, fins i tot en els esforços d'individuar els textos que bateguen sota els versos, la presència dels quals, però, es pot tan sols conjecturar a través d'indicis mínims, com quan, davant de "Nuvial", Duran (2004, p. 138) constata que Maragall descriu Itàlia 
per la seva calidesa "deixant-se emportar per les seves lectures de Goethe, on el tema apareix amb recurrència".

Queda per calcular l'ajut que manllevava de les versions franceses de Goethe al moment de traslladar el text alemany a la seva llengua, però és indubtable que tenia davant seu els llibres en original i que els podia llegir. En encarar-se a un text grec, la situació era ben diferent, ja que tot començava amb una primera versió en prosa que Bosch Gimpera trametia "per parts a Joan Maragall; després, el jove hel·lenista anava a casa del poeta, per declamar-li passatges del text grec en veu alta, aparentment amb la finalitat que Maragall s'amarés del ritme de l'original, i, alhora, per aclarir-li els dubtes que anessin sorgint" (Alsina \& Pòrtulas, 2009, p. 53-54). Al darrere, hi ha una altra complicació: la relació que Maragall instaura amb els monuments de l'antiguitat. Coincideixo amb Quintana (2020, p. 20-21), segons el qual "Eurípides, decididament, no era un referent per a Maragall com Ésquil ho era per a Masriera: el referent de Maragall era Goethe" i que, d'altra banda, la Ifigènia "s'inclou en el programa modernista d'actualitzar la cultura catalana i en un programa més ampli, especialment intens a França, de recuperació de la cultura grega". Però apartem aquestes connexions indirectes, i centrem-nos en el resultat més elaborat d'aquest esforç global: la recuperació i l'actualització dels Himnes Homèrics. Entre les mil referències a la Ilíada i l'Odissea, n'hi ha una si més no curiosa en una carta a Pijoan del 1r de setembre de 1908. Maragall li explica que, estant de vacances a Olot, es dedica a passejar les nenes i a llegir-los Bousset i Plutarc, "i com els agrada Homer! No sols les aventures, sinó el modo de dir que els faig entendre a voltes de l'italià: E tu cosi li respondesti [sic], Eumeo". No és tant la passió de les nenes el que importa aquí, sinó l'aspecte tècnic d'un text grec llegit en la versió de Pindemonte. És, en definitiva, el primer pas cap al gir ideològic que presenta, el 21 de juny de 1910, en parlar de l'Oda I de Píndar:

Jo de primer no ho volia fer, perquè sempre m'han repugnat les traduccions indirectes; però ho he temptejat, i Píndaro, que mai m'havia entusiasmat, ha començat a interessar-me molt, i me sembla que faré no una traducció, certament, però una mena de fantasia pindàrico-catalana.

I en tot s'aprèn, o no és veritat? I de tractar amb un com Píndaro (encara que sia per intèrpret) sembla que un n'ha de quedar ennoblit, i el nostre parlar també.

(Maragall, 1960, p. 1051-1052)

Aquest moviment engloba també la funció de la traducció, on s'entreveu una estratègia semblant a allò que en altres escrits havia caracteritzat la pràctica de la imitació. Crec que Ramon Torné dona suport a la meva idea que en Maragall s'activa una intertextualitat en forma de xarxa quan comenta que "podria ser inesperadament fructífer un acostament a Nausica tenint in mente el contacte de Maragall amb l'Olímpica I i, molt possiblement, de l'Himne homèric a Demèter" (1999a, p. 79). En fi, originals i traduccions tot és u, vindrien ganes de glossar, però no és ben bé així. Quan entrem dins els Himnes Homèrics, hi ha un aspecte relativament nou amb el qual el torsimany s'ha 
d'enfrontar, ja que, a la necessitat de familiaritzar-se amb el model de versió del grec antic, s'hi afegeix la imprecisió de la reproducció "bàrbara" de la mètrica. El que acabo de dir és un resum en píndoles d'allò que Alsina \& Pòrtulas (2009) ja han sostingut a partir d'un element força indicatiu d'aquesta dialèctica: el trasllat dels "epítets formulars" i les tries que les seves reiteracions o modificacions comporten. Amb aquesta focalització específica, eviten el parany tautològic sobre l'harmonització al català dels versos antics, un motiu que Carles Riba (1967, p. 100-120) feu servir per lloar Maragall tot agraint-li la feina feta, a diferència d'Eduard Valentí (1973, p. 43-49), que confutarà aquestes raons amb una anàlisi detallada i impietosa. El debat ha estat viu i apassionat, però té un defecte de base: les edicions dels Himnes publicades pòstumament són plenes de correccions normalitzadores que no pertanyen a la mà de Maragall, i no podem saber fins a quin punt l'autor les hauria acceptades. Molt més sensat hauria estat agafar els manuscrits -que són complets i estan redactats d'una manera molt avançada- i limitar-se a la intentio auctoris. Hi ha hagut qui, després d'haver col-lacionat l'edició de l'Institut de la Llengua Catalana i la lliçó "retocada" dins el volum de les Obres Completes publicades per Gustau Gili - totes dues van sortir l'any 1913- arriba a augurar-ne una futura publicació "no només ad fidem codicum, sinó recollint les vicissituds de la història del text" (Torné, 2001, p. 93). Tanmateix, sempre que no apareguin unes galerades fantasmagòriques, el pas definitiu serà l'edició dels manuscrits dels Himnes que veurà la llum en el cinquè volum de les noves Obres Completes.

Descarto de bell nou la possibilitat de capbussar-me en el joc de miralls entre els Himnes i la Nausica, i m'estimo més ressaltar aquells versos que, en la traducció, recorden molt de prop la poesia maragalliana o, si fa no fa, la seva musicalitat. Penso, concretament, en el trasllat d'una imatge de l'himne "A Apol·ló Piti". Mentre el fill de Leto entra al palau de Zeus tocant la lira, i totes les Muses l'acompanyen amb el cant, un altre grup es dedica a la dansa. Pere Bosch Gimpera tradueix el v. 1966,

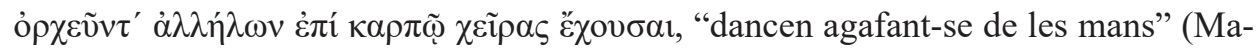
ragall, 1913), mentre que Balasch (1974) proposa "dansen donant-se les mans nuades pel puny l'una a l'altra". Si passem a la versió maragalliana, no trobarem, dins la semàntica, cap indici sospitós, i no obstant això, el resultat està directament vinculat a la poètica del traductor. Només cal escandir les síl·labes del vers incriminat:

se dónen les máns l'una a l'áltra i coméncen la dánsa; i amb élles

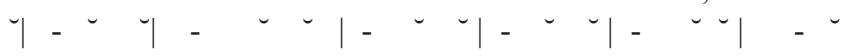

Si acceptem -i no veig altre remei- la presència de l'anacrusi inicial, es desplega una cadència dactílica de manual. La precisió és, però, un element del tot secundari front a la progressió constant dels accents triàdics: amb aquest ritme, i amb la corres-

${ }^{6}$ La numeració l'extrec de Balasch (1974) que manté la continuïtat (ergo, la progressió) entre els dos himnes. Així, doncs, la part dedicada “A Apol·ló Piti” comença amb el v. 181. 
pondència que té amb el contingut del vers, qui pot evitar de pensar en "La sardana"? I si el dístic inicial del poema de Visions \& Cants -que es repeteix a tall de coda a cada estrofa- n'és un primer indici -"La sardana és la dansa més bella / de totes les danses que es fan i es desfan" (v. 1-2)-, què dir de la imatge que en domina la part final: "és la dansa sencera d'un poble / que estima i avança donant-se les mans" (v. 43-44)? Això sí: he de reconèixer que, a aquesta lectura, ja hi havia arribat Maria-Mercè Marçal, sense tenir la possibilitat de consultar el text manuscrit. Després de citar "La sardana", afirma que:

[...] retinguem aquesta unitat dels versos 10-11: sis accents distribuits regularment segons un ritme ternari, preferentment dactílic, en alguns casos aconseguit amb accents secundaris, i una unitat de ritme formada mètricament per un decasíllab clàssic català i un pentasíl·lab: $(4+6)+5$. Potser de la combinació d'aquests dos criteris pot sorgir la pauta de la traducció dels Himnes homèrics i explicar que aquests "hexàmetres" funcionin tot i una manifesta irregularitat en la distribució dels accents. (Marçal, 2018, p. 88)

Per afegir més arguments a aquesta lectura, assenyalaré una altra ressonància de "La sardana" lligada a un vers que es troba gairebé al final de l'himne anterior, "A Apol-ló Deli": "Saben els cants i les danses sonores de totes les gents, / i semblen oir-se en una veu sola: l'acorden talment!". El dístic maragallià resumeix tres versos (162-164), que Bosch Gimpera tradueix: "Elles saben imitar la veu i les dances de tots els homens acompanyades dels címbals $i$ apar que se senti distintament la veu de cadascuna: de tal manera composen llur cant formós!". El subjecte plural són les donzelles de Delos de les quals es descriuen les celebracions. En el primer vers de Maragall, amb cinc dàctils i una paraula monosil·làbica accentuada al final ("sáben els cánts i les dánses sonóres de tótes les génts"), el ritme és aclaparador i sembla acompanyar les noies al compàs.

Tot i amb tot, és fàcil deixar-se encisar per imatges que es juxtaposen a la poètica de l'autor català sense deixar de ser meres coincidències. Poso sobre la taula una de les meves cartes més febles: 1'“Himne a Demètera" [sic] ens pot suscitar, amb les escenes d'afecte vers l'infant, records vagues que van des de "Paternal" fins a "Retorn d'Haidé". Respecte a aquest últim cas, penso en la comparació que s'obre ex abrupto amb la dida que ha hagut de deixar el nen i que, mig amagada, torna a esguardar-lo de lluny. I això ressona, com a contrapunt, a la imatge de "Primer dol" (Seqüencies), on el deslletament ve a ser, als ulls de l'infant, una crueltat injustificada. Ara bé, a la versió de Bosch Gimpera ("Era ungit amb ambrosía [sic], com si d'un déu fos nat, per Demèter, qui, tenint-lo al si, alenava suaument sobre d'ell"), Maragall ja ho tenia tot preparat, i l'única llibertat que es pren és l'adjectivació afegida: “[...] que, tenint-lo al si, suaument / li infonia amb la boca l'alè de son pit immortal" (v. 206-207). La "nodriça" esdevé la "dida" i, un parell de vegades, gairebé com si fos un epítet tot 
maragallià, l'infant és qualificat de "tendre": si aquí, en l'estil del traductor, queda una latència de les creacions del poeta, es tracta d'un factor insensible a l'emulsió fotogràfica més general que he volgut perfilar.

Comptat i debatut, als Himnes només podem cercar-hi els petits écarts del torsimany que desperten la suspicàcia del lector, i procedir cap enrere per esbrinar-ne els possibles orígens. Però aquests indicis són tan intangibles que les meves suposicions esdevenen més lleugeres que l'aire. Davant una composició relativament anodina com "A la mare dels déus", la qual es complau "a l'udol dels llops, / i al bram dels lleons d'ulls encesos" (v. 3-4), ens quedaríem estupefactes si comparàvem aquesta versió amb la de Balasch ("l'udol del llop i el del lleó de pell roja"), però l'expressió $\chi \alpha \rho \circ \pi \omega ́ v$ no resulta gens ambigua, i Maragall tenia al seu costat, com a canovaccio, la traducció de Bosch Gimpera: "l'udol dels llops, el bramul dels lleons d'ulls esplendents". Doncs bé, encara podríem insistir dient que els "ulls encesos" ens remeten a "L'estimada de Don Jaume", on el sintagma ja s'havia produit en tot un altre context (això és, l'enamorament de Jaume I per Mallorca). Les formes són idèntiques, però quin valor té una repetició que, com a molt, pot ser considerada un estilema d'autor?

\section{CONCLUSIONS}

Els exemples que he aportat són numèricament massa petits per assolir una funció paradigmàtica, però he limitat la meva recerca amb la intenció de generar un model buit a priori que podré omplir en un segon moment.

Així, doncs, d'una banda, no he volgut fer servir el microscopi, i no he remarcat la reiteració del mig riure i dels seus derivats, que formen probablement la isotopia més forta de tot el teixit semàntic maragallià i que abunden, en particular, en algunes traduccions, entre les quals la dels Himnes Homèrics. D'altra banda, no he volgut eixamplar, amb el telescopi, l'horitzó òptic de la meva indagació i m'he cenyit a les correspondències amb la creació poètica. Perquè tot aquest discurs s'enquadra dins una estratègia textual molt més ampla, amb una precipitació d'elements manllevats, desplaçats i recuperats, ja que les confluències, en Maragall, substitueixen les més típiques influències. Només hi persisteix una traça feble dels originals coberta pels jocs de ressonàncies que reflecteixen, tot multiplicant-los, els estímuls provats pel poeta. Un pas enrere, i podem parlar d'un Maragall pioner en la reflexió sobre la traducció (Fulquet, 1995, p. 70); un pas endavant, i ens haurem d'enfrontar, un cop més, a un Maragall teòric de la literatura.

I no dic més, perquè, entre els manuscrits de la versió maragalliana dels Pensaments de Goethe trobo un avís o, millor dit, una interdicció que m'impedeix passar aquestes fronteres: "el microscopi i el telescopi perverteixen la puresa del sentit humà". 


\section{AGRAÏMENTS}

Aquest treball s'inscriu dins el projecte d'investigació del Ministerio de Ciencia e Innovación FFI2017-86542-P titulat La literatura de segundo grado: las relaciones hipertextuales en la literatura catalana desde el "Modernisme" hasta 1939. Més informació sobre l'activitat del grup investigador a: http://www.uv.es/ironialitcat/. 


\section{REFERÈNCIES BIBLIOGRÀFIQUES}

Alsina, V. \& Pòrtulas, J. (2009). A propòsit de la versió dels Himnes Homèrics de Joan Maragall. Dins M. Ortín \& D. Pujol (eds.). Llengua literària i traducció (p. 51-80). Lleida: Punctum.

Ardolino, F. (2006). Una literatura entre el dogma i l'heretgia. Les influències de Dante en l'obra de Joan Maragall. Barcelona: Cruïlla.

Aulet, J. (1992). Josep Carner i els orígens del Noucentisme. Barcelona: Curial.

Balasch, M. (1974). Himnes Homèrics. Versió poètica catalana. Barcelona: Curial.

Bosch Rabell, M. (2018). El pensamiento romántico de Maragall. Contrastes. Revista Internacional de Filosofia, XXIII (1), 59-76. DOI: 10.24310/Contrastescontrastes.v23i1.5463

Campi, R. (2000). Joan Maragall i J. W. Goethe. La influència de l'escriptor alemany en el pensament civil de Maragall. Els Marges, 68, 13-49.

Cerdà i Surroca, M. À. (1981). Els pre-rafaelites a Catalunya. Barcelona: Curial.

Cornudella, J. (2018). "Jo li he obert l'última porta”. Notes sobre Nausica en la poesia de Maragall. Haidé. Estudis maragallians, 7, 29-44.

Duran, M. (2004). Una mostra primerenca de la influència de Goethe sobre Maragall: la sèrie "Claror". Zeitschrift für Katalanistik, 17, 131-154.

Eisner, C. (2009). Maragall, Joan. Dins F. Lafarga \& L. Pegenaute (eds.). Diccionario histórico de la traducción en España (p. 752-753). Madrid: Gredos.

Foster, B. (2007). The Songs of Edvard Grieg. Woodbridge: Boydell Press.

Fulquet, J. M. (1995). Recreación, adaptación, asimilación, imitación. Quimera, 140-141, 68-70.

Gavagnin, G. (2007). Traducció i reescriptura. A propòsit de les traduccions d'Esclasans de poesia italiana. Els Marges, 83, 61-76.

Huysmans, J.-K. (1895). Là-bas. París: Tresse \& Stock.

Maragall, J. (1913). Himnes Homèrics. Traducció en vers de Joan Maragall i text grec amb la traducció literal de P. Bosch Gimpera. Barcelona: Institut de la Llengua Catalana.

Maragall, J. (1960). Obra Completa, 1. Barcelona: Selecta.

Maragall, J. (2007). Com si entrés en una pàtria (ed. de G. Casals). Barcelona: Publicacions de l'Abadia de Montserrat.

Maragall, J. (2020). Obres completes, I (ed. de L1. Quintana \& I. Moreta). Barcelona: Edicions 62.

Marçal, M.-M. (2018). Entorn dels hexàmetres maragallians (ed. de J. Pujol). Haidé. Estudis maragallians, 7, 83-101.

Miralles, C. (2003). L'èpic i el tràgic. Sobre la poètica de l'últim Maragall. Dins Professor Joaquim Molas: memòria, escriptura, història, II (p. 721-741). Barcelona: Publicacions de la Universitat de Barcelona.

Moreta, I. (2014). Ernest Hello: les motivacions d'una traducció de Maragall. Haidé. Estudis maragallians, 3, 119-125.

Murgades, J. (2019). El Goethe de Maragall o com es pot suplir "la falta d'una tradició literària pròpia i seguida". Quaderns. Revista de traducció, 26, 33-49.

Novalis (2016). Heinrich von Ofterdingen. Berlín: Hofenberg Sonderausgabe.

Palol, M. de (2016). Obra poètica completa. Girona: Curbet Edicions.

Pons, J. S. (1914). Notes de Littérature Catalane. Revue Catalane, VIII (91), 186-193.

Quintana, L1. (1996). La veu misteriosa. La teoria literària de Joan Maragall. Barcelona: Publicacions de l'Abadia de Montserrat.

Quintana, Ll. (2020). "Pròleg”. Dins J. Maragall. Ifigènia a Tàurida (p. 9-25). Barcelona: Institut del Teatre.

Riba, C. (1967). Obres Completes, 2: Assaigs crítics. Barcelona: Edicions 62.

Torné, R. (1999a). Traducciones catalanas de los poemas homéricos. Tempus, 23, 5-15. 
Torné, R. (1999b). Joan Maragall traductor d'Hesíode? Faventia, 21 (1), 139-143.

Torné, R. (2001). Sobre l'edició dels Himnes homèrics de Joan Maragall per 1'IEC. Dins: A. Roca (ed.). Actes del Simpòsium "L'aportació cultural i científica de l'Institut d'Estudis Catalans” (p. 87-93). Barcelona: Institut d'Estudis Catalans.

Torrent, R. (2011). Maragall, Joan. Dins M. Bacardí \& P. Godayol (eds.). Diccionari de la traducció (p. 314-316). Vic: EUMO.

Tur, J. (1974). Maragall i Goethe. Les traduccions del Faust. Barcelona: Universitat de Barcelona. Valentí, E. (1973). Els clàssics i la literatura catalana moderna. Barcelona: Curial. 